\title{
HUBUNGAN DUKUNGAN KELUARGA DENGAN KUALITAS HIDUP PASIEN KANKER SERVIKS DI RUMAH SAKIT IBNU SINA MAKASSAR PERIODE JANUARI-JUNI 2017
}

\author{
Hidayati, Subriah \\ Jurusan Kebidanan Poltekkes Makassar
}

\begin{abstract}
ABSTRAK
Dukungan keluarga terhadap pasien kanker sangat dibutuhkan untuk meningkatkan mental dan semangat hidup pasien kanker, juga sangat diperlukan dalam hal psikologis kaitannya dengan penurunan kecemasan sehingga berpengaruh terhadap kualitas hidup pasien. Setiap perempuan beresiko terkena kanker serviks tanpa memandang usia dan latar belakang. Kanker serviks dan kanker payudara yang menempati urutan tertinggi di Indonesia. Kemoterapi merupakan cara pengobatan kanker yang paling banyak dilakukan (Azwar 2007), namun dapat menimbulkan ketidaknyamanan, meningkatkan stres dan mempengaruhi kualitas hidup klien. Tujuan penelitian ini untuk mengetahui hubungan dukungan keluarga dengan kualitas hidup pasien kanker serviks di rumah sakit ibnu sina makassar. Jenis penelitian ini adalah penelitian epidemiologi dengan determinan analitik yang menggunakan pendekatan Cross - Sectional yaitu dengan melakukan pengukuran sesaat untuk mengambil hubungan antara dukungan keluarga dengan kualitas hidup pasien kanker serviks. Hasil penelitian menggunakan korelasi Pearson Product Moment diketahui bahwa nilai korelasi hitung sebesar 0,413 dengan nilai probabilitas 0,023 ( $\rho$ value $<0,05$ ), terdapat hubungan yang signifikan antara dukungan keluarga dengan kualitas hidup pada pasien kanker serviks.
\end{abstract}

Kata kunci Kanker Serviks, Kualitas hidup. Dukungan keluarga

\section{A. Pendahuluan}

Keluarga adalah dua orang atau lebih yang disatukan oleh kebersamaan dan kedekatan emosional serta yang mengidentifikasi dirinya sebagai bagian dari keluarga. Keluarga juga didefenisikan sebagai kelompok individu yang tinggal bersama atau tidak adanya hubungan darah, pernikahan, adopsi dan tidak hanya terbatas pada ke angotaan dalam satu rumah tangga. Dukungan keluarga adalah sikap, tindakan dan penerimaan keluarga terhadap penderita yang sakit. Anggota keluarga memandang bahwa orang bersifat mendukung selalu siap memberi pertolongan dan bantuan jika diperlukan. Adanya perhatian dan kasih sayang, nasehat, dan bantuan yang diberikan anggota keluarga yang akan memberikan rasa tenang dan aman kepada pasien. Dukungan sosial adalah suatu keadaan yang bermanfaat bagi individu yang diperoleh dari orang lain yang dipercaya, sehingga individu tersebut tahu bahwa ada orang lain yang memperhatikan, menghargai dan mencintainya (Friedmen,2010).

Dukungan keluarga terhadap pasien kanker sangat dibutuhkan untuk meningkatkan mental dan semangat hidup pasien kanker. Dukungan keluarga juga sangat diperlukan dalam hal psikologis kaitannya dengan penurunan kecemasan sehingga berpengaruh terhadap kualitas hidup pasien. Setiap perempuan beresiko terkena kanker serviks tanpa memandang usia dan latar belakang. Di Asia Pasifik, tiap tahun ditemukan sekitar 266.000 kasus kanker serviks, 143.000 diantaranya meninggal dunia pada usia produktif. Setiap tahun terdapat kurang lebih 400.000 kasus baru kanker serviks, sebanyak $80 \%$ terjadi pada wanita yang hidup di negara berkembang. Sedangkan di Indonesia, terdapat 40 -45 kasus baru kanker serviks setiap hari dan menyebabkan kira - kira 20 - 25 kematian perhari. Tingginya kasus di negara berkembang karena akses informasi tentang penyakit kanker serviks yang masih terbatas, termasuk skrining dan pengobatan.

Kanker serviks dan kanker payudara yang menempati urutan tertinggi di Indonesia. Kanker serviks sebesar (0,08\%), kanker payudara berada di urutan kedua dengan angka prevalensi $(0,05 \%)$, kanker prostat $(0,02 \%)$ Kasus kanker yang tinggi di Indonesia disebabkan oleh kurangnya kesadaran untuk melakukan deteksi dini sehingga sebagian besar ditemukan pada stadium lanjut. Akibatnya, banyak penderita yang tidak tertolong. Kemoterapi merupakan cara pengobatan kanker yang paling 
banyak dilakukan (Azwar 2007). Komplikasi kemoterapi juga dapat menimbulkan ketidaknyamanan, meningkatkan stres dan mempengaruhi kualitas hidup klien.

Pengambilan data pada tanggal 26 januari 2016 data dari Rekam Medik Rumah Sakit Ibnu Sina Makassar jumlah penderita gangguan kesehatan reproduksi dari bulan Januari sampai Desember tahun 2016 sebanyak 458 pasien. Di antaranya, kanker serviks sebanyak 92 pasien (20\%), tumor mammae 110 (24\%) pasien, kanker mammae 128 (28\%) pasien, mioma uteri $42(9,2 \%)$ pasien, kista dermoid 2 $(0,2 \%)$, kista ovarium $38(8,3 \%)$ pasien, kanker endometrium $14(3,1 \%)$ pasien, tumor adneksa $2(0,4 \%)$ pasien, abses payudara 18 (4\%) pasien, PID 12 $(2,6 \%)$ pasien.

B. Metode

\section{Jenis Penelitian}

Jenis penelitian ini adalah penelitian epidemiologi dengan determinan analitik yang menggunakan pendekatan Cross - Sectional yaitu dengan melakukan pengukuran sesaat untuk mengambil hubungan antara dukungan keluarga dengan kualitas hidup pasien kanker serviks di rumah sakit lbnu Sina makassar.

2. Populasi dan Sampel

Populasi dalam penelitian ini yaitu semua pasien kanker serviks yang di rawat di Rumah Sakit Ibnu Sina Makassar pada bulan Maret sampai Juni 2017. Sampel dalam penelitian ini adalah sebagian pasien kanker serviks yang dirawat di Rumah Sakit Ibnu Sina Makassar pada bulan Maret sampai Juni 2017 yaitu sebanyak 30 pasien. Pengambilan sampel dalam penelitian ini menggunakan non probability sampling dengan teknik sistematik Random Sampling. Pengambilan sampel yang didasarkan atas pertimbangan sesuai dengan criteria inklusi dan eksklusi.

\section{Hasil Penelitian}

\section{Karateristik Responden}

Karateristik responden dalam penelitian ini membahas tentang usia, pendidikan, pekerjaan. Hal ini dapat dijelaskan dalam tabel 4.3 sebagai berikut.

Tabel 1

Pengelompokan Karateristik Berdasarkan Umur

\begin{tabular}{|c|c|c|}
\hline Karateristik & $\begin{array}{c}\text { Frekuensi } \\
\text { (f) }\end{array}$ & (\%) \\
\hline $\begin{array}{l}\text { Umur: } \\
<30 \text { tahun } \\
30-40 \text { tahun } \\
>40 \text { tahun } \\
\text { Jumlah : }\end{array}$ & $\begin{array}{c}1 \\
3 \\
26 \\
30\end{array}$ & $\begin{array}{c}3,3 \\
10 \\
86,7 \\
100\end{array}$ \\
\hline
\end{tabular}

Sumber : Data Primer 2017

Berdasarkan distribusi umur responden, diketahui bahwa 1 orang $(3,3 \%)$ berumur kurang dari 30 tahun, 3 orang (10\%) berumur antara $30-40$ tahun, dan 26 orang $(86,7 \%)$. Sehingga dapat diketahui bahwa responden sebagian besar mempunyai umur lebih dari 40 tahun yaitu sebesar $26(86,7 \%)$.

Tabel 2

Pengelompokan Karateristik Berdasarkan Jumlah Anak

\begin{tabular}{lcc}
\hline \multicolumn{1}{c}{ Karateristik } & $\begin{array}{c}\text { Frekuensi } \\
(\mathbf{f})\end{array}$ & $(\%)$ \\
\hline Jumlah Anak : & & \\
$<\mathbf{3}$ & 11 & 36,7 \\
$>\mathbf{3}$ & 19 & 63,3 \\
Jumlah : & $\mathbf{3 0}$ & $\mathbf{1 0 0}$ \\
\hline Sumber : Data Primer 2017 & &
\end{tabular}


Dari jumlah anak responden diketahui bahwa dari 30 responden terdapat 11 orang $(36,7 \%)$ mempunyai anak kurang dari 3 dan 19 orang
$(63,3 \%)$ yang mempunyai anak lebih dari 3 anak. Hal ini berarti mayoritas responden mempunyai anak lebih dari 3 yaitu sebanyak 19 (63,3\%).

Tabel 3

Pengelompokan Karateristik Berdasarkan Pendidikan

\begin{tabular}{|c|c|c|}
\hline Karateristik & $\begin{array}{c}\text { Frekuensi } \\
\text { (f) }\end{array}$ & $(\%)$ \\
\hline Pendidikan : & & \\
\hline SD & 6 & 20 \\
\hline SMP & 2 & 6,7 \\
\hline SMA & 9 & 30 \\
\hline PT & 5 & 16,7 \\
\hline & 8 & 26,7 \\
\hline Jumlah : & 30 & 100 \\
\hline
\end{tabular}

Sumber : Data Primer 2017

Pendidikan responden diketahui bahwa dari 30 responden diketahui terdapat 6 orang $(20 \%)$ lulus SD, 2 orang $(6,7 \%)$ berpendidikan SMP, 9 orang $(30 \%)$ berpendidikan SMA, 5

Tabel 4

orang $(16,7 \%)$ orang perguruan tinggi, dan 8 orang $(26,7 \%)$ orang tidak sekolah. Hal ini berarti mayoritas responden berpendidikan tidak Sekolah yaitu sebanyak 8 orang ( $26,7 \%)$.

Pengelompokan Karateristik Berdasarkan Pekerjaan

\begin{tabular}{lcc}
\hline \multicolumn{1}{c}{ Karateristik } & $\begin{array}{c}\text { Frekuensi } \\
(\mathbf{f})\end{array}$ & $\mathbf{( \% )}$ \\
\hline Pekerjaan : & & 13,3 \\
PNS & 4 & 6,7 \\
Wiraswasta & 2 & 13,3 \\
Buruh / Petani & 4 & 66,7 \\
IRT & 20 & $\mathbf{1 0 0}$ \\
Jumlah : & $\mathbf{3 0}$ & \\
\hline
\end{tabular}

Sumber : Data Primer 2017

Dilihat dari jenis pekerjaan responden diketahui bahwa yang mempunyai pekerjaan PNS sebanyak 4 orang $(13,3 \%)$, sebagai wiraswasta sebanyak 2 orang $(6,7 \%)$, sebagai

buruh/petani sebanyak 4 orang $(13,3 \%)$, dan IRT sebanyak 20 orang $(66,6 \%)$. Hal ini berarti mayoritas responden mempunyai pekerjaan sebagai IRT yaitu 20 orang $(66,6 \%)$.

\section{Analisis Univariat}

a. Dukungan Keluarga

Hasil distribusi frekuensi tentang dukungan keluarga disajikan dalam tabel 4.8 sebagai berikut :

Tabel 5

Distribusi Frekuensi Tentang Dukungan Keluarga

Di Rumah Sakit lbnu Sina Makassar

\begin{tabular}{lcc}
\hline Dukungan Keluarga & Frekuensi & $(\%)$ \\
\hline Kurang & 14 & 46,7 \\
Baik & 16 & 53,3 \\
jumlah & $\mathbf{3 0}$ & $\mathbf{1 0 0}$ \\
\hline
\end{tabular}

Sumber : Data Primer 2017 
Berdasarkan distribusi data tentang dukungan keluarga pada pasien kanker serviks sebagian besar mempunyai dukungan keluarga yang baik sebanyak $16(46,7 \%), 14$ orang $(53,3 \%)$ yang mempunyai dukungan keluarga kurang.

\section{Tabel 6}

Distribusi Frekuensi Tentang Kualitas Hidup Di Rumah Sakit lbnu Sina Makassar

\begin{tabular}{|c|c|}
\hline Kualitas Hidup & Frekuensi \\
\hline $\begin{array}{l}\text { Kualitas hidup Baik } \\
\text { Kualitas hidup kurang } \\
\text { Jumlah }\end{array}$ & $\begin{array}{l}43,3 \\
56,7 \\
100\end{array}$ \\
\hline $\begin{array}{l}\text { Sumber: Data Primer } 2017 \\
\text { Berdasarkan distribusi data } \\
\text { tentang kualitas hidup pasien kanker } \\
\text { serviks sebagian besar mempunyai } \\
\text { c. Analisis Bivariat } \\
\text { 1. Uji Kolmogrof ( Uji Normalit } \\
\text { Uji Kolmogrof Ten } \\
\text { Di Rumah Saki }\end{array}$ & $\begin{array}{l}\text { kualitas hidup baik sebanyak } 13 \text { orang } \\
(43,3 \%) \text {, dan } 17 \text { orang }(56,7 \%) \text { yang } \\
\text { mempunyai kualitas hidup kurang. } \\
7 \\
\text { Dukungan Keluarga } \\
\text { Sina Makassar }\end{array}$ \\
\hline Maen & $\begin{array}{c}\text { Asymp. Sig. (2- } \\
\text { tailed) }\end{array}$ \\
\hline 0,0000000 & 0,45890210 \\
\hline
\end{tabular}

Test Distribution Normal

Berdasarkan output diatas diketahui bahwa nilai signifikansi sebesar 0,052 lebih

besar dari 0,05 sehingga dapat disimpulkan bahwa data yang telah di uji berdistribusi normal.

\section{Uji Hipotesis}

Analisis bivariat digunakan

untuk menerankan keeratan hubungan b. Kualitas Hidup

Hasil distribusi tentang kealitas hidup pasien kanker serviks disajikan dalam tabel 4.9 sebagai berikut. kualitas hidup baik sebanyak 13 orang $(43,3 \%)$, dan 17 orang (56,7\%) yang mempunyai kualitas hidup kurang as) 
Berdasarkan tabel diatas dengan menggunakan korelasi Pearson Product Momentdiketahui bahwa nilai korelasi hitung sebesar 0,413 dengan nilai probabilitas 0,023 ( $\rho$ value $<0,05$ ) sehingga Ha diterima dan Ho ditolak, artinya bahwa terdapat hubungan yang signifikan antara dukungan keluarga dengan kualitas hidup pada pasien kanker serviks.

\section{Pembahasan}

Pada pembahasan ini akan membahas mengenai hasil penelitian yang berhubungan dengan hubungan dukungan keluarga dengan kualitas hidup pasien kanker serviks.

Menurut teori bomar (2006), dukungan keluarga adalah bentuk perilaku melayani yang dilakukan oleh keluarga, baik dalam bentuk dukungan emosional (perhatian, kasih sayang, empati), dukungan penghargaan (menghargai, umpan balik), dukungan informasi (saran, nasehat, informasi) maupun dalam bentuk dukungan instrumental (bantuan tenaga, dana, dan waktu). Kualitas hidup didefenisikan sebagai persepsi individu mengenai posisi mereka dalam kehidupan dalam konteks budaya dan sistem nilai di mana mereka hidup dan dalam kaitannya dengan tujuan, harapan standar dan perhatian mereka (Nofiori, 2009).

Hasil penelitian ini sesuai dengan penelitian yang dilakukan oleh Mujianto tentang hubungan dukungan keluarga dengan kualitas hidup pasien kanker di RSUP Dr. Mohammad Hosein Palembang. Berdasarkan hasil analisa korelasi spearmen diketahui bahwa tingkat signifikasi $p=0,006$. Ada hubungan yang signifikan antara dukungan keluarga dengan kualitas hidup pasien kanker.

Hasil penelitian ini diperkuat penelitian yang dilakukan oleh sari, dkk(2012), yang meneliti tentang hubungan dukungan keluarga terhadap motivasi pasien kanker dalam menjalani kemoterapi, hasil penelitian yang didapatkan $p$ value $=0,008$ ( $p$ value < $0,05)$ dengan $\mathrm{OR}=9.000(95 \% \mathrm{Cl}=1,958$ 41,364), artinya Ho ditolak, sehingga disimpulkan bahwa terdapat hubungan yang signifikan antara dukungan keluarga terhadap motivasi pasien kanker payudara dalam menjalani kemoterapi.

Hasil dalam penelitian ini sesuai dengan saragih (2010) yang mengemukakan adanya hubungan yang bermakna $(p=0,001)$ antara dukungan keluarga dengan kualitas hidup pasien hemodialisis. Istiqomah (2009) meneliti 35 pasien hemodialisis di surabaya, dan hasilnya menunjukan bahwa pasien yang menerima perhatian, kehangatan, dan pertolongan dari keluarganya akan lebih bersemangat menjalani hidup dan meningkat kualitas hidupnya. Penelitian ini menunjukan adanya hubungan yang signifikan antara dukungan sosial dengan penerimaan diri dan kualitas hidup pasien hemodialisis $(p=0,000)$. Semakin tinggi dukungan sosial yang diterima pasien akan semakin meningkatkan penerimaan diri dan kualitas hidupnya.

Hasil penelitian ini juga sejalan dengan penelian yang dilakukan oleh Rijalul Hakim dan Teguh Anjar Baskoro (2013) yaitu Hubungan Dukungan Keluarga dengan Kualitas Hidup Pasien Kanker yang Menjalani Kemoterapi di Rumah Sakit Kraton Pekalongan. Terdapat hubungan yang bermakna antara dukungan keluarga dengan kualitas hidup pasien kanker yang menjalani kemoterapi di RSUD Kraton Pekalongan dengan $\rho$ value sebesar 0,014 . Dari hasil penelitian ini diharapkan tenaga kesehatan juga memotivasi keluarga untuk dapat memberikan dukungan keluarga kepada pasien kanker dan juga keluarga diharapkan ikut serta dalam berbagai tindakan selama pasien tersebut menjalani kemoterapi sehingga dapat memberikan kenyamanan bagi pasien yang menjalani kemoterapi sehingga dapat meningkatkan kualitas hidup pasien kanker.

Hasil Peneliti dengan menggunakan korelasi Pearson Product Momentdiketahui bahwa nilai korelasi hitung sebesar 0,413 dengan nilai probabilitas 0,023 ( $\rho$ value $<0,05$ ) sehingga Ha diterima dan Ho ditolak, artinya bahwa terdapat hubungan yang 
signifikan antara dukungan keluarga dengan kualitas hidup pada pasien kanker serviks.

Asumsi peneliti, dengan adanya dukungan keluarga sangat membantu pasien untuk meningkatkan keyakinan akan kemampuannya dalam melakukan tindakan perawatan diri. Pasien kanker yang berada dalam lingkungan keluarga dan diperhatikan oleh anggota keluarganya akan dapat menimbulkan persaan nyaman dan aman sehingga akan tumbuh rasa perhatian terhadap dirinya. Menurut peneliti rasa nyaman yang timbul pada diri pasien akan muncul karena adanya dukungan baik emosional, penghargaan, instrumental dan informasi dari keluarga. Selain dukungan dari keluarga dukungan dari perawat juga sangat di butuhkan karena selain keluarga orang yang sering dijumpai yaitu perawat, perawat dapat memberikan dukungan kepada pasien dalam mengambil keputusan untuk melakukan pengobatan. Jadi intinya dukungan dari keluarga dan perawat sangat dibutuhkan mengingat pasien kadang mengalami masalah psikologi terkait dengan penyakit yang dideritanya.

\section{E. Kesimpulan}

Berdasarkan hasil penelitian tentang hubungan dukungan keluarga dengan kualitas hidup pasien kanker serviks di Rumah Sakit Ibnu Sina Makassar dapat disimpulkan bahwa ada hubungan antara dukungan keluarga dengan kualitas hidup pasien kanker serviks di Rumah Sakit Ibnu Sina Makassar.

\section{F. Saran}

Berdasarkan kesimpulan penelitian maka disarankan kepada keluarga untuk memberikan motivasi bagi pasien kanker yang menjalani pengobatan agar lebih patuh terhadap jadwal dan pengobatan kanker seperti kemoterapi. Bagi peneliti lain bisa menggunakan variabel lain yang belum diteliti, seperti sikap, pengalaman, lingkungan dan fasilitas kesehatan.

\section{DAFTAR PUSTAKA}

Ali Zaidin, 2010. Pengantar Keperawatan Keluarga. Jakarta ; EGC.

Friedman, et al, 2010. Buku Ajar Keperawatan Keluarga : Riset Teoridan Praktik, Alih Bahasa, AkhirYanis, Hamid dkk, eds. Jakarta : EGC.

Fitriana, N. A., 2012, 'Kualitas Hidup Penderita Kanker Serviks yang Menjalani Pengobatan Radioterapi', Jurnal Psikologi Klinis dan Kesehatan Mental, vol. 1 , no. 2, hh. 123-129.

Farida, 2010. "Pengalaman Klien Hemodialisis Terhadap Kualitas Hidup dalam Konteks Asuhan Keperawatan di RSUD Fatmawati, Jakarta". Universitas Indonesia, Tesis, Depok.

Hakim Rijalul, 2013. Hubungan Dukungan Keluarga dengan Kualitas Hidup Pasien Kanker yang Menjalani Kemoterapi di RSUD Kraton

Pekalongan.http://www.eskripsi.stikesm uhpkj.ac.id/eskripsi/index.php?p=f streampdf\&fid $=425 \&$ bid $=480$.

Nursalam, 2011. Konsep dan Penerapan Metodologi Penelitian IImu Keperawatan Pedoman Skripsi, Tesis dan Instrumen Penelitian Keperawatan, Sumba Medika ; Jakarta.

Nomora Lamongga Lubis, 2011. Dukungan Sosial pada Pasien Kanker, Perlu kah ?. Medan ; USU Press.

Prawirohardjo Sarwono. IImu Kandungan. Jakarta. PT. Bina Pustaka Sarwono Prawirohardjo; 2012

Rasjidi Imam. Epidiemologi Kanker Serviks. Tanggerang. Journal Of Canser.2009 
Suhud, M, 2009, 'Apakah Kualitas Hidup Itu?', Dialife, April, h. 4.

Supriyadi, Wagiyo dan Widowati, 2011. "Tingkat Kualitas Hidup Pasien Gagal Ginjal Kronik terapi Hemodialisis". Jurnal Kesehatan Masyarakat Universitas Negeri Makassar.
Saragih, Rosita, 2010, 'Peranan Dukungan Keluarga dan Koping Pasien Dengan Penyakit Kanker terhadap Pengobatan Kemoterapi di RB 1 Rumah Sakit Umum Pusat Haji Adam Malik Medan Tahun 2010', Tesis MKep, Universitas Darma Agung. 